\title{
Correction
}

\section{Correction to: A Review of Battery Fires in Electric Vehicles}

Peiyi Sun and Xinyan Huang (D), Research Centre for Fire Engineering, Hong

Kong Polytechnic University, Kowloon, Hong Kong

Roeland Bisschop, Department of Fire Research, RISE Research Institutes of

Sweden, Borås, Sweden

Huichang Niu, Guangzhou Industrial Technology Research Institute, Chinese

Academy of Sciences, Guangzhou, Guangdong, China

\section{Correction to: Fire Technology}

https://doi.org/10.1 007/s $10694-01$ 9-00944-3

The original version of this article unfortunately contained an incorrect unit of PHRR for Eq. (3), which appears in abstract and conclusion, and an incorrect version of Fig. 23.

For Eq. (3), $P H R R=2 E_{B}^{0.6}$, the correct unit of $P H R R$ is $\mathrm{kW}$.

The correct Fig. 23 is given below.
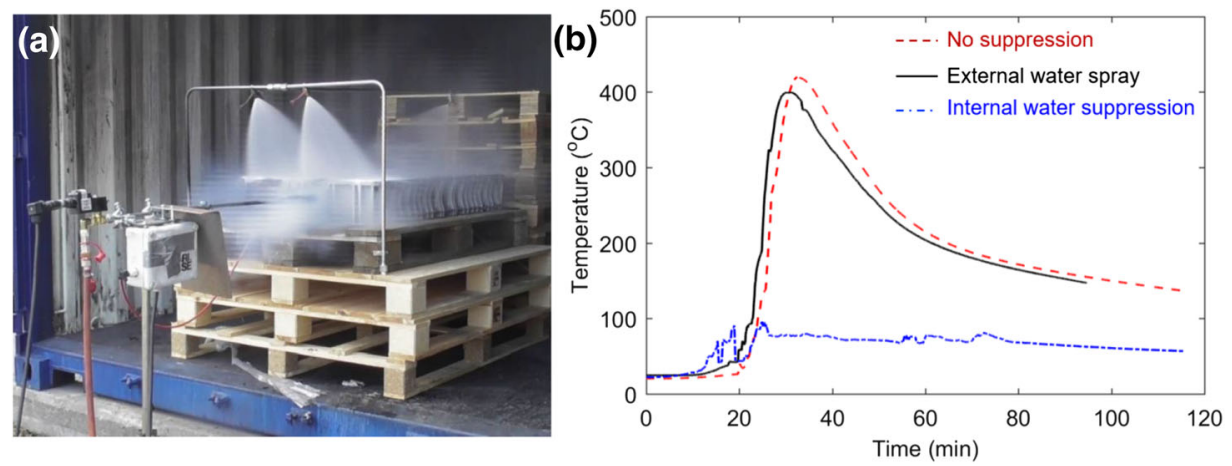

Figure 23. (a) A photograph of the suppression test for EV battery fire and (b) the temperature measurement of a battery near ignition location under different fire-suppression techniques [ 159 ].

Publisher's Note Springer Nature remains neutral with regard to jurisdictional claims in published maps and institutional affiliations.

* Correspondence should be addressed to: Xinyan Huang, E-mail: xy.huang@polyu.edu.hk

The original article can be found online at https://doi.org/10.1007/s10694-019-00944-3. 